\title{
Chinese Traditional \\ Management Philosophy and Project Risk Management
}

\author{
Anbang Qi \\ Business School of \\ Nankai University, China \\ qabang@163.com
}

DOI 10.5592/otmcj.2015.1.1

CHINESE TAKE PROJECT RISK MANAGEMENT AS THE KEY OF A PROJECT SUCCESS. THE MAIN REASON IS THE INFLUENCE OF THE TRADITION PHILOSOPHY AND CULTURAL OF CHINESE. There are many historical Chinese books deal with the law of changes for risk management. The most important book is named "Book of Changes" that influenced Chinese management philosophy and methodology more than 6000 years. There are two main cultural schools of Chinese originated from this book. All these make Chinese believe that project change and risk management are the most important thing in project management because all certain things have fixed results but all uncertain things have different results depended on people management.

\section{Keywords}

Chinese philosophy, Change management, Project risk management 


\section{INTRODUCTION}

Project risk management is one knowledge area in all European and American project management styles. There is the project risk management knowledge area in A Guide of Project Management Body of Knowledge (PMBOK) $^{1}$ by Project Management Institute(PMI). And there exists the same thing in IPMA Competence Baseline (ICB) ${ }^{2}$ of International Project Management Association (IPMA).

But Chinese style of project risk management are different in attitude, principle and methods to project risk management because of the influences and effects of traditional Chinese cultural and management philosophy. The most influence comes from a book named Book of Changes ${ }^{3}$ originated more than 6000 years ago. And there are two main schools of Chinese cultural, the Taoism and Confucian who also influence the Chinese style of project risk management. Both of them started more than 2700 years ago and all originated from different editions of the Book of Change.

\section{The influence of the observation by} ancient Chinese

The Book of Changes is originated from the observations of ancient Chinese about all changes in the world. First of all, they found the sky changes since the sun is on during the day time and the moon is on during the night time. Then they found the earth changes because mountains raised in somewhere and rivers cut down in somewhere. They also found human being changes as some of them become men and others become women. And they found even animals and plants changes as some of

1 The standard committee of PMI, A Guide of Project Management Body of Knowledge, 5 th edition, PMI, 2012.

2 International Project Management Association, IPMA Competence Baseline, 3 rd edition, IPMA, 2013.

3 Sun, Honggang, Book of Change and Strategies, New World Press, Beijing, 2010. them become males and others become females.

At last, they made the conclusion that all these changes and all changes are cause by two original powers or elements, Yin (with the abstract like - -) and Yang (with the abstract like $\longrightarrow$ ). They are the unity of two opposites that makes the world change and develop. Therefore, they got the attitude that change is the only things people need to manage because people can decrease loses and increase benefits through the changes control. As a matter of fact, this is a kind of attitude about risk management as well as project risk management.

One ancestor or god of Chinese named Fu Xi (BC3272-3157) ${ }^{4}$ founded or invented the Eight Diagrams (eight combinations Yin and Yang) as the eight drivers that cause all changes. From then, Chinese use the eight diagrams to identify and control all changes of all things. They apply that in the agricultural industry and they have Spring Planting, Summer Growing, Autumn Harvest and Winter Storage. And they apply these in Chinese medicine to dell the illness like Yang is too strong and Yin is too wake or in contrast. All these are illustrated in the figure 1 as follows.

The influence of the Book of Change Then anther ancestor king of Chinese named Yan Di (BC 3103-2986) 5 founded or invented the first edition of the Book of Changes that including 64 doubled diagrams that combined two single Fu Xi's Eight Diagrams. That Book of Changes is named as Lian Shan Yi because the first combination in it is about the changes of mountains. That shows Yan Di and his people thinks mountain is the center of the world and everything in the world changes caused by the change of the mountain. From

\footnotetext{
4 Du Songqi, Research on Fu Xi Cultural, China Social Science Press, 2013.

5 Lei, Shaosheng, Yan Di: Thousands Years History Earlier than BC, HuBei People Press, 2011.
}

then, Chinese use that Book of Changes for managing changes and risks. For example, they apply these principle and method in Chinese traditional Feng Shui for construction project management, and these started to forecast crisis or emergency by observation of changes. In fact, that Book of Changes is the first book about change and risk management in Chinese history and that tells how everything changes, how to deal with all these changes, and how to make good use of all these changes.

About 300 years later, one more ancestor king of Chinese named Huang Di (BC2697-2494) invented or edited the second edition of the Book of Changes. This Book of Changes is named as Gui Cang Yi. The main different of this edition form Lian Shan Yi is that the first combination is about changes of the earth, but not mountains. That shows Huang Di and his people believes that the earth is the center of the world and everything in the world changes caused by the change of the earth. That is a great progress in the outlook or attitude of Chinese about the world. Huang Di has written another book named Huang Di Nei Jing 7 that is the origination of Chinese medicine. From that time, Chinese start use the change of the 4 seasons of the sky and the 24 solar periods of the earth for agricultural and other things. In fact, Chinese start to make good use of changes management to get wealthy and healthy and to do things in accordance with the law of changes about the earth from that time and that make Chinese own some special nature in change and risk management.

About another 1400 years later, another ancestor king of Chinese named Zhou Wen Wang (BC1152-1056) ${ }^{8}$ edited

\footnotetext{
6 Liu Mingwu, Cultural of Huang Di and Cultural of Emperor, Shenzhen, Sea and Sky Publishing Co. 2010.

7 Yao Chunpeng edited and noted, Huang Di Nei Jing Beijing, Chinese Press, 2010

8 Yang Li, Zhou Wen Wang, Beijing, China Chinese Federation, 2014.
} 


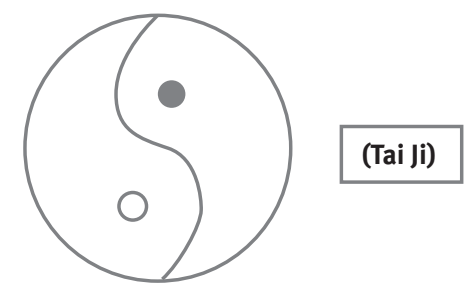

Figure 1.

the Eight Diagrams

System of Fu Xi

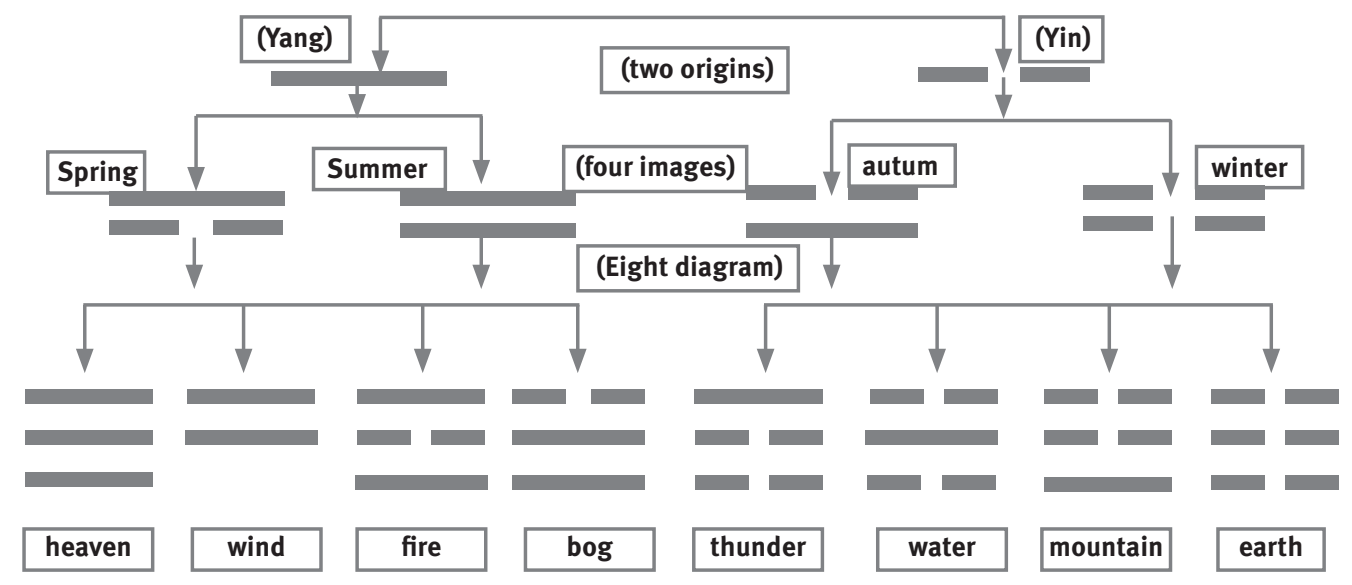

or invented the third edition of the Book of Changes. This Book of Changes is named as Zhou Yi. The main different of former two editions is that the first combination of this edition is about changes of the heaven. That shows Zhou Wen Wang and his people believes that the heaven is the center of the world and everything changes in accordance with the change of the heaven. It is an of big other great progress in the outlook or attitude of Chinese about the world. Zhou Wen Wang and his successors use these theory in their governance of the country and that made Zhou Dynasty is the only dynasty that lasts for more than 800 years. And that also affects China to maintain as on country for more than 5000 years. Chinese start to make good use of changes and risk management in both the nature world and in the human society and society. In fact, all Chinese cultural and management philosophy, even nowadays, are based on these three editions of Book of Change.

\section{The influence of Daoism}

About another 500 years later in Dong Zhou Dynasty (BC770 to BC221), China is in the time of hundred schools of thoughts. All these schools applied the theory of the Book of Change into different aspects or areas. And two main schools of them remained till now is the Daoism and Confucian. They form the core ideas, attitudes and contents of Chinese cultural and management philosophy focused on the change and risk management for productivities, societies and countries.

The founder of Daoism school is Lao Zi (BC $\left.570-B C_{470}\right)^{9}$. His book named Dao De Jing has a great influence on Chinese cultural about changes and risks management. All principles of the Gui Cang Yi has explained in this book and all the methods of how to deal with changes and risk management is discussed in this book. In fact, this book only contains 4800 Chinese characters, but it last about 2700 years, and it is introduced into western world more than 400 years and has an influence worldwide. The main ideas in the thesis statement of that book is as follows.

\footnotetext{
9 Lao Zi, edited and noted by Qiu Ye, Dao De Jing,
} Shanghai, Golden Shield Publishing Co., 2013.
When people can tell the law of something (e.g. project), that is not always the law of that thing because that thing can change along with the time.

People have no information of a new thing (e.g. project) at the beginning and they will have complete information at the end of that thing.

- Therefore, people need to forecast or foretell the change of that thing (e.g. project) without prejudice, and do feasibility study to find out if their goal can come true.

$\checkmark$ A thing (e.g. project) changes again and again. People should have right attitude and methods to deal with all changes and to find the right way to do things.

All these ideas can be illustrated in the figure 2. It shows that there always exist some information gap at the beginning of a project. Especially, there is no any information about the new project. There may be some historical similar project information but not the new project's information. And later on, people get some information of the new project planning and design. The new project's information gap is made up step by step 


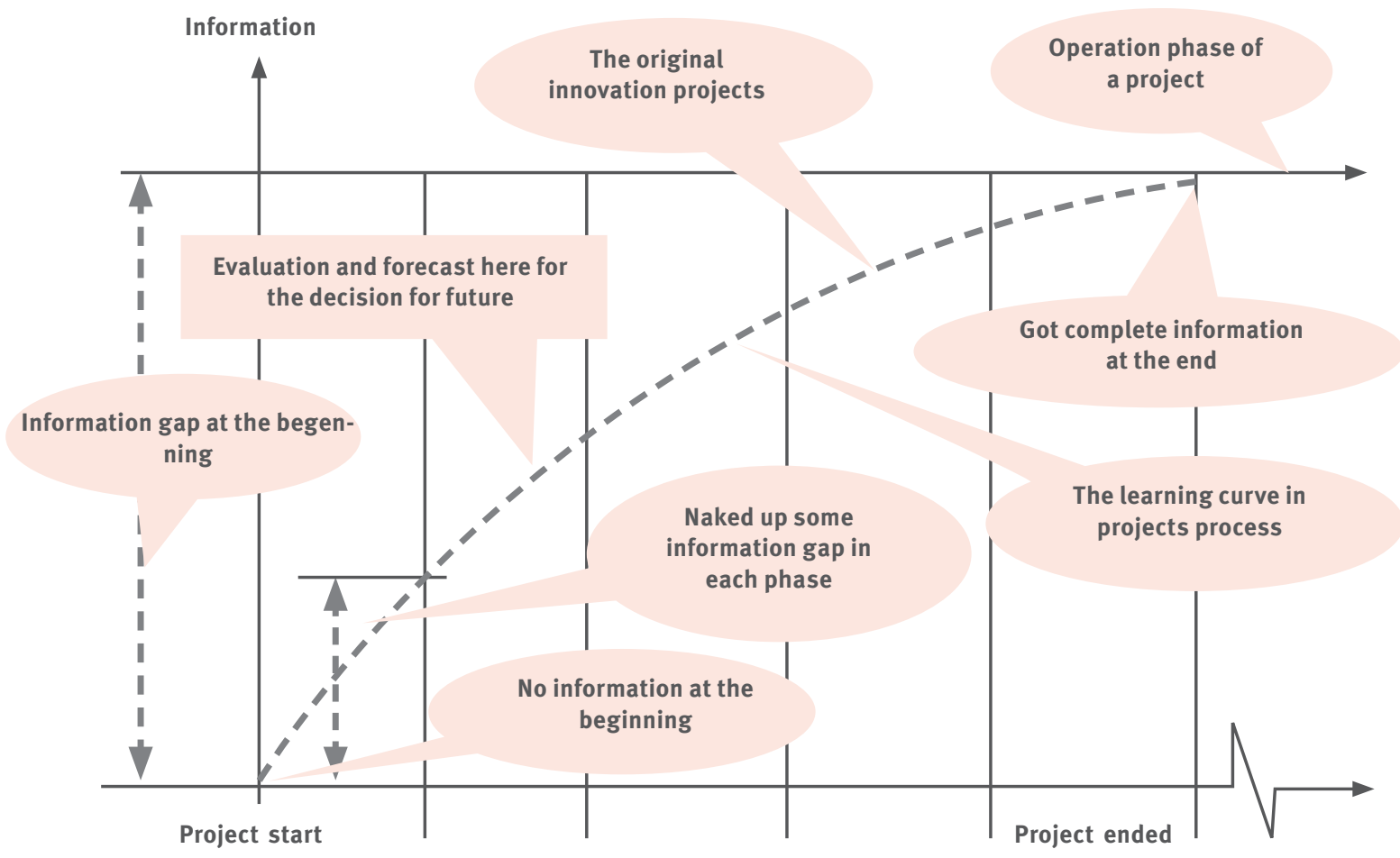

Figure 2. The illustration of the ideas in the book of Dao De Jing

when people get more information along with the project execution. At last, people get the complete information of the project and make up the information gap completely. Therefore, the whole project process is a learning process and that forms the learning curve that is shown by the figure 2 .

The influence of Confucian

The founder of Confucian school is Confucius $\left(\mathrm{BC}_{551-\mathrm{B} C} 479\right)^{10}$. His book of $\mathrm{Yi}$ Zhuan has a greater influence on Chinese cultural, governance and management. All principles of the Zhou Yi has explained in this book and the methodology for dealing with changes is discussed in that book from the point of view how to make good use of changes to govern the family, the

10 Yan Tao, Confucius and Confucian, Shanghai, The Commercial Press, 2000. country and the world. As a matter of fact, this book is not only last about 2700 years but also introduced and influenced all eastern and western countries for many years. The main ideas in this book is as follows.

Zhou Yi is the book about the law of the whole world and the principles in Zhou Yi is exactly the explanation of the law of nature about changes of the world.

Zhou Yi comes from people's observation of the sky and the earth. Therefore, it tells the truth of the world for people to deal with the change of the world.

> People will not be against the law of nature if they know the law and people will be success if they do things (e.g. projects) in accordance with the law.

The unity of opposites of Yin and Yang is the law of nature. All successes come from obey this law of nature. Manager or governor must know this law of nature.

Change means something is new to the world. Therefore, innovation day by day is the sublime virtue to a manager or governor, and getting their people richer and richer is the most important thing that managers/ governors should do.

In summary, the book of Yi Zhuan is also a book for change and risk management. But it emphasize on the harmonious or unity of opposites of Yin and Yang in changes and change management. Confucian believes that everything is changing and these changes cause different results of things. When people have some information about a thing that is an independent innovation project and when people have no information about a thing that is an original innovation project, all these two kind things or projects need the change or risk management. The figure 3 can illustrate these two kind situations of changes 


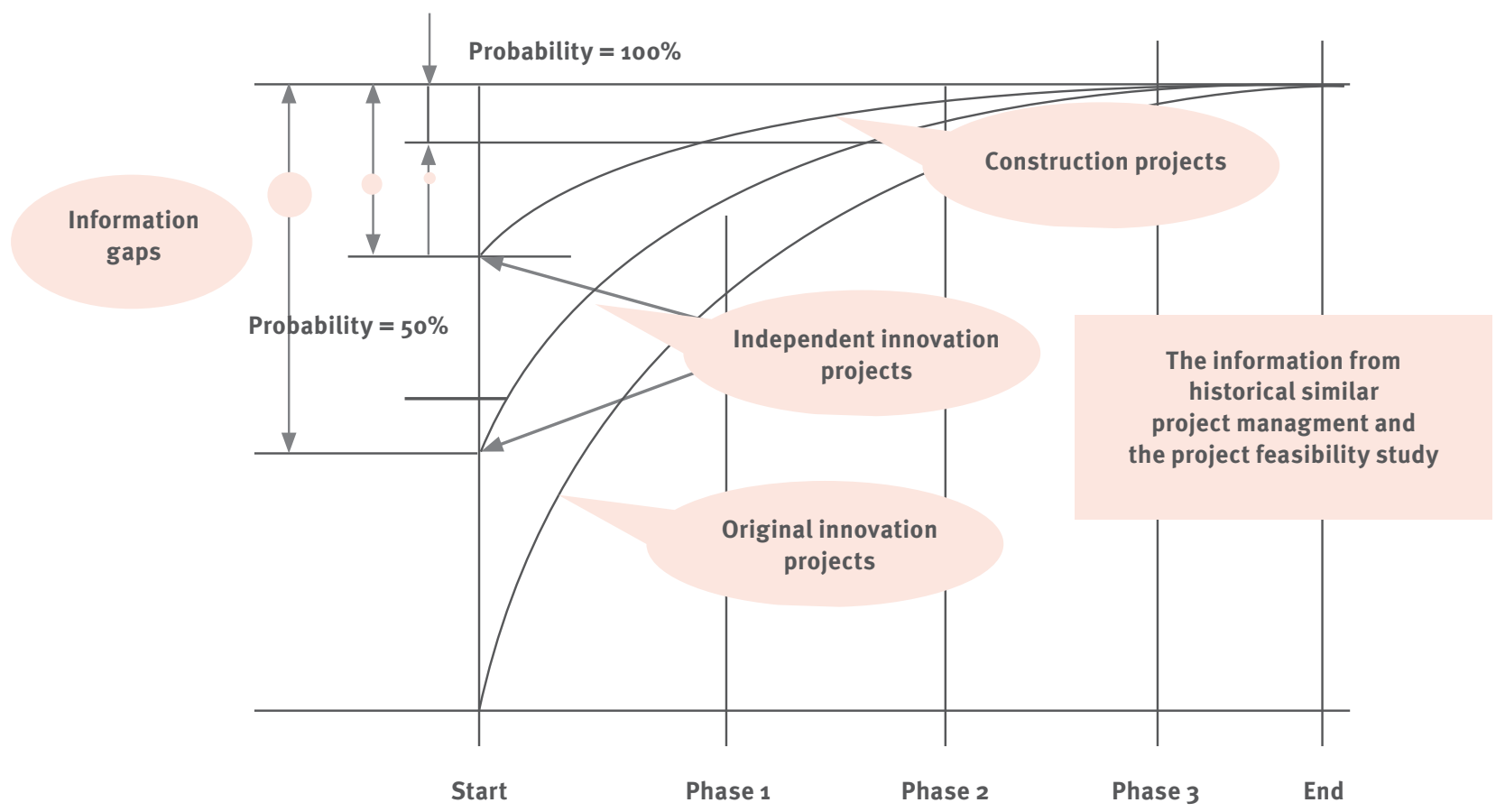

Figure 3: The illustration of information gaps for different projects

or risks. The figure 3 shows that there is no information for original innovation projects at the beginning because people have not done this kind of things of projects and there is no any historical similar project information to refer to and that is why this kind of thing or project is called original innovation project. The figure 3 also shows that there is some information for independent innovation projects at the beginning because there are some historical similar projects information people can refer to for the new independent innovation projects. At the end of any kinds of projects (including construction projects), people get the complete information of a project because that project is ended and will never change again.

\section{The Chinese attitudes and ideas of} project risks management

In summary, the main difference between Daoism and Confucian school is that Daoism focus on the law of nature about changes or risks and Confucian emphasize make good use of the law of nature about changes or risk management. Chinese use the theories and methods of Daoism to find the law of change or risks in what they are doing and use the theories and methods of Confucian to find the way for risk management for what they will do in the near future. That is why these two Chinese cultural and management schools can last 2700 years together because they are just like Yin and Yang that are unity of opposites. The mixture of these two theories or thoughts consists the Chinese cultural and management philosophy.

According to Chinese cultural and management philosophy, the main work in project management is the management because project is uncertain. Chinese think project risks is the possibility of loss / earning for project stakeholders that is caused by changes of the project conditions and environments or even the change of the project stakeholder's mind. ${ }^{11}$ This can be expressed by the formula language as follows:

$$
R=P \times(L / E)
$$

11 Qi Anbang, Project Risk Management, Tianjin, Nankai University press, 2007.
In the formula, R means a project risk, $P$ means the probability of a project risk, $L$ means the loss that may be caused by the project risk, E means the earning that may be caused by the project risk. This formula tells the truth that project risks not only can result in losses but also can bring some earnings.

Chinese think project risks management contains three kinds of project management works: to get more information and better cognation about the project, project conditions and environments, to decrease the loss caused by project risks, and to increase the earning raised by project risks ${ }^{12}$. This can be expressed by the formula language as follows:

$$
\mathrm{PRM}=\mathrm{P} \uparrow \mathrm{x}(\mathrm{L} \downarrow / \mathrm{E} \uparrow)
$$

In this formula, PRM means project risk management, $\mathrm{P} \uparrow$ means increasing project, information in order to reduce the uncertainties of the project, $L \downarrow$ means decreasing the losses caused

12 Qi Anbang, Project Management, Beijing, China Science Press, 2013. 
by project risks $\mathrm{E} \uparrow$, means increasing the earnings through project risk management. This formula tells the truth that project risk management not only can decreasing losses but also can increasing earnings.

In fact, there exists some difference in the idea, attitude and methods towards risks and risk management between Chinese and western. For example, in financing and insurance industry defined the risk as the probability of loss $(R=P x L)$. They persuade people to buy their insurance products in order to avoid the loss caused by risks. As a matter of fact, project risk and risk management should be defined as formula 1 and formula 2 . 